\title{
Indications and Success Rate of Endo Crowns - A Systematic Review
}

\author{
Shahzeb Hasan Ansari ${ }^{1}$, Abdullah Ahmed Alfaqeeh², Abdullah Al Buryk ${ }^{3}$, Sara Ahmed Alfaqeeh ${ }^{4}$, \\ Abdullatif Yousif A. Almusharraf ${ }^{5}$, Atheer Hussain N. Aljarullah ${ }^{6}$ \\ 1, 4 College of Dentistry, Riyadh ELM University, Riyadh, Saudi Arabia. \\ 2, 3, 5, 6 MOH Dental Clinics, Riyadh, Saudi Arabia.
}

\section{ABSTRACT}

\section{BACKGROUND}

Endodontically treated teeth are most commonly restored using post-retained foundation restoration and a crown which has certain well-established drawbacks. Nowadays, the emergence of minimal invasive dentistry has led to increased use of endocrowns for restoring such teeth. However, their indications and success rates have not been explored widely enough to merit their full implementation in dental practice. This systematic review attempts to achieve this purpose by accumulating evidence from current literature that underscores endocrowns' indications and success rates.

\section{METHODS}

The electronic search strategy was performed in three databases (PubMed, Google Scholar, and EBSCO) using MeSH terms endocrowns, or endocrown success rates of endocrowns or endo crowns in dentistry or endodontically treated teeth or ceramic or monoblock or CAD-CAM, confined to articles published between $1^{\text {st }}$ January 2015 and $20^{\text {th }}$ November of 2019. All selected articles were evaluated to determine as to whether or not they could be included in the SR. Abstracts and titles were screened independently by 2 investigators and duplicates if any were removed. For possible inclusion after reading abstract, full-text assessment of the article was performed based on eligibility criteria. Manual extraction of data from the retrieved publications was done.

\section{RESULTS}

A total of 20 articles was found on related topic from electronic and manual searching, out of which, 2 were duplicates and hence removed. Further 7 articles were removed in screening and again 2 were removed after reading full-text, thus making the final count of 9 articles for the systematic review. Among the nine articles, 3 were clinical studies, 1 was a retrospective patient series study, while remaining were in-vitro studies. Out of 9, 7 articles (77 \%) reported endocrowns to be successful and 2 articles (22\%) gave contrary outcomes.

\section{CONCLUSIONS}

Most of the articles included in this SR agree that endocrowns are a desirable restorative tool in dentistry. Other systematic reviews and meta-analyses with a significant number of included publications and studies should be conducted to expand the generalizability potential of such results.
Corresponding Author: Dr. Shahzeb Hasan Ansari, Lecturer, Department of Preventive Dentistry, College of Dentistry, Riyadh ELM University, Riyadh -11681, Saudi Arabia.

E-mail: shahzebhasan@riyadh.edu.sa

DOI: $10.14260 / j e m d s / 2020 / 712$

How to Cite This Article:

Ansari SH, AlFaqeeh AA, Al Buryk A, et al. Indications and success rate of endo crowns - a systematic review. J Evolution Med Dent Sci 2020;9(43):3247-3251, DOI: $10.14260 /$ jemds/2020/712

Submission 04-07-2020,

Peer Review 15-09-2020,

Acceptance 21-09-2020,

Published 26-10-2020.

Copyright (C) 2020 Shahzeb Hasan Ansari et al. This is an open access article distributed under Creative Commons Attribution License [Attribution 4.0 International (CC $B Y 4.0)]$

\section{KEY WORDS}

Endocrowns, Restoration, Success 


\section{BACKGROUND}

The topic of endodontically treated teeth (ETT) is always a controversial one that has led to different views and opinions from scholars and researchers who focus on adding more information about the same to existing dental literature. ETT conveys a greater danger of biomechanical failure than fundamental teeth and are a regular issue in restorative dentistry identified with the fractures occurring in such teeth. ${ }^{1}$ Usually, the biomechanical failure of ETT can be attributed to specific factors.

The alterations in the biomechanical features and essential teeth integrity are in all likelihood ascribed to the hard tissues' volumetric loss, degree of carious sore, fracture proliferation, last cavity planning notwithstanding the access cavity before the start of endodontic treatment. ${ }^{2}$ In this regard, there is still a discussion concerning which procedure would be perfect for the restoration of ETT, since specific teeth are believed to possess an elevated danger of breakage than other vital ones. The durability of endodontic management is affected by the aspects like a suitable restoration that safeguards tooth structure and category of restorative materials. For providing a solid foundation for the restoration and also to augment the structural strength of the repaired tooth, quality and integrity of the left over tooth structure should be conserved cautiously. It has been pointed out by the biomechanical principles that the extent and intrinsic strength of hard tissues along with the anatomic form integrity, is responsible for the structural strength of a tooth. ${ }^{1}$ The restoration which is most commonly utilized for such teeth involves a post-retained foundation restoration and a crown. ${ }^{3,4}$ The insertion of post increases the retention of the core foundation. On the other hand, it also causes weakening of tooth structure and thus elevates risk of root fractures. ${ }^{5}$

When considering a biomimetic viewpoint, the safeguarding and protection of the structure of teeth are principal in keeping up the equilibrium between parameters, mechanical, organic, cement, and practical. ${ }^{2}$ It is gainful to safeguard tissues of the coronal plane and evade intrusive endodontic strategies because these methodologies disrupt the biomechanical equilibrium and compromise the long-haul execution of repaired teeth.

With the beginning of adhesion and progress of effective dentin adhesives a true advancement occurred in the reestablishment of endodontically treated teeth. By using adhesive restorations, the need for mandatory macroretentive elements was no longer required if sufficient surface is existing. This approach has made the incorporation of radicular posts an exception as compared to compulsory insertion while using conventional restorative systems. The restoration of ETT by minimally invasive measures and maximal tissue preservation, are nowadays regarded as 'the gold standard'. As prosthetic option in restoration of ETT with excessive tissue loss, endocrowns are useful by following this rationale. Endocrown technique was first used by Pissis and has expressed it as the 'mono-block porcelain technique'. New horizons were opened in processing of restorative materials and in the restoration of teeth by the growth of computeraided design / computer-aided manufacturing (CAD / CAM) technology offering precision, aesthetics, and shortening the time required for restorative procedure. Bindle and Mörmann explained the endocrown for the first time as adhesive endodontic crowns and considered as total porcelain crowns anchored to endodontically treated posterior teeth. These crowns would be fixed to the interior part of the pulp chamber and on the cavity margins, so macro mechanical retention is offered by the pulpal walls, and micromechanical retention is attained by the use of adhesive cementation. In cases with extreme loss of crown tissue, inadequate inter-proximal space and inability to rehabilitate with traditional post and crown due to insufficient ceramic thickness, this technique is predominantly indicated. The endocrowns offer a variety of advantages as compared to conventional crowns such as endocrowns are easy to apply, require a short preparation time and chair-side time, low cost, and aesthetics. Besides, endocrowns are also a choice in teeth with short or atresic clinical crowns, calcified, curved or short root canals that make post application impossible. ${ }^{1}$

In the recent era, there has been advancements in the adhesive techniques and growth of minimally invasive dentistry, owing to which endocrowns are gaining popularity as alternatives to the fixed partial and conventional post-core denture that can be used to restore excessively damaged ETT. ${ }^{1}$ Endocrowns are good alternatives for restoring molars that possess substantial coronal damage and present difficulties in endodontic treatment. ${ }^{6,7}$ In this regard, endocrowns seem to have desirable outcomes when used to repair damaged ETT. However, their indications and success rate have not been explored widely enough to merit their full implementation in dentistry practice. Therefore, studies should be done to pinpoint various signs and rates of endocrowns success in restoring excessively damaged ETT. This systematic review attempts to achieve this purpose by accumulating evidence from current literature that underscores endocrowns indications and success rate.

\section{METHODS}

This SR was reported according to the PRISMA (Preferred Reporting Items for Systematic Reviews and Meta-Analysis) guideline. ${ }^{8}$ Therefore, it was adhered to in this SR, as can be seen in Figure 1.

\section{Protocol and Registration}

Enlistment of the protocols of SR is often an essential endeavour since it expands the openness and accessibility of literature evaluation methods. Additionally, it decreases inclination in SR and odds of duplication. These situations have prompted the foundation of databases like PROSPERO that permit free enlistment of SR. ${ }^{9}$ Nonetheless, this SR was not enlisted. In such a way, no information can be given concerning the enrolment number or where the method can be retrieved on the web. The information exhibited in this paper is an exceptional procedure that can be used in various examinations of a comparative sort.

\section{Search Strategy}

This process alludes to the strategies used to help with searching for the necessary sources to be included in the SR. In this case, a far-reaching search of existing sources was 
performed in three databases. They included PubMed, Google Scholar, and EBSCO. The three databases were picked because they comprise of a vast extent of health related publications that are current, dependable, and appropriate to numerous themes or subjects. Along with the electronic search, a manual search from the references of the selected articles was conducted. The databases could not be searched without catchphrases or Medical Subject Headings (MeSHs). MeSHs are frequently used as essential analytical components. ${ }^{10}$ They can be regarded as sources to an information body kept as booklets or papers in a database. ${ }^{11}$ In this precise preview, a portion of the MeSHs and catchphrases that were utilized to help the inquiry included endocrowns, OR endocrown success rates $\mathrm{OR}$ endo crowns in dentistry OR endodontically treated teeth OR ceramic OR monoblock OR CAD-CAM confined to articles published between $1^{\text {st }}$ January 2015 and $20^{\text {th }}$ November of 2019.

\section{Eligibility Criteria}

This section of the SR presents the limits of any given review. The qualification criteria regularly show the limits of some precise random survey. It comprises both the inclusion and exclusion criteria. The inclusion criterion required articles with content focusing on the indication and success rate of endo crowns, studies with any design, investigation conducted and written in any region of the world, and any report published in English. As for the exclusion criterion, it necessitated the removal of all articles published in any other language other than English and publications with content that did not conform to the topic of interest, which was indications and success rate of endo crowns.

\section{Definitions}

This part of the SR comprises the descriptions of different terminologies that were used. Usually, those descriptions are often designed in a way that depicts how they are utilized in the SR. Therefore, when you compare the descriptions given in the SR and those provided by other scholars and researchers, a slight difference often exist. Even so, in this SR, not unique terminologies were used to warrant a description or definition. Every one of the terms utilized as depicted by the meanings and description accorded to it by different researchers and analysts because of their pertinence to the topic of interest. This data, therefore, is the rationale for not including any definitions or descriptions of terms used in this SR.

\section{Study Selection}

The entire selected articles were evaluated to determine whether or not they could be included in the SR. The abstracts and titles were screened independently by 2 investigators and any duplicates were removed. For possible inclusion after reading abstract, full-text assessment of the article was performed based on eligibility criteria. Both the reviewers discussed and resolved any discrepancies which were found at the end.

\section{Extraction of Information}

Manual extraction of data from the retrieved publications was done. Necessary data from the chosen studies were accumulated and recorded in tabular form. Since this review concentrated on recognizing the indications and success rate of endo crowns, the data retrieved from the chosen articles included the author(s), publication year, study design, and outcomes of the examinations. The outcomes segments of the studies gave data concerning the indications and success rate of endo crowns.

\section{RESULTS}

This review discovered exciting facts that are related to the topic of concern. Even so, the first finding worth stipulating is the retrieval process of articles included in the SR. In total, the number of materials contained in the SR was twenty. This figure was the sum of thirteen publications that were retrieved from the databases and seven that were obtained through other means, like assessing the references of the articles obtained from the databases. The titles of these twenty articles were evaluated, and duplicates were removed, an undertaking that led to the remainder of eighteen publications. When the titles and abstracts of these eighteen reports were screened, it was discovered that seven of them did not conform to the topic of interest. Therefore, they were removed, and only eleven studies remained. The next step involved subjecting the eleven articles to an eligibility test, which excluded two studies. ${ }^{12,13}$ (Table 1) Thereby, only nine publications remained which were included in the SR. [Figure 1]

\begin{tabular}{|c|c|c|}
\hline Author & Year & Reasons for Exclusion \\
\hline Rocca et al ${ }^{12}$ & 2016 & Non-Monolithic Endocrown \\
\hline Helal and Wang ${ }^{13}$ & 2017 & $\begin{array}{c}\text { Endocrowns are Compared with Multiple Post } \\
\text { Restorations }\end{array}$ \\
\hline \multicolumn{3}{|c|}{ Table 1. List of Studies Excluded } \\
\hline
\end{tabular}

\section{Study Characteristics}

Among the nine articles, only three of them were clinical studies, accounting for 33 percent of the entire publications included in the SR. One was a retrospective patient series study, while remaining were in-vitro studies. (Table 2) Even though diversity can be pinpointed when considering the studies' designs, they still focused on the same topic, which was to indicate the success rate of endocrowns as dental tools that can be utilized to restore ETT.

\section{Success Rate of Endocrowns}

Out of 9,7 articles (77 \%) reported endocrowns to be successful and 2 articles (22\%) gave contrary outcomes. Maximum scholars and researchers that performed those particular investigations discovered that endocrowns have a high success rate as an alternative treatment process for ETT. For example, Hamdy ${ }^{14}$ posit that endocrowns' high success rate can be attributed to its resistance to fracture. In their studies, they found out that when endocrowns are used to restore teeth, they do not erode fracture quickly. 


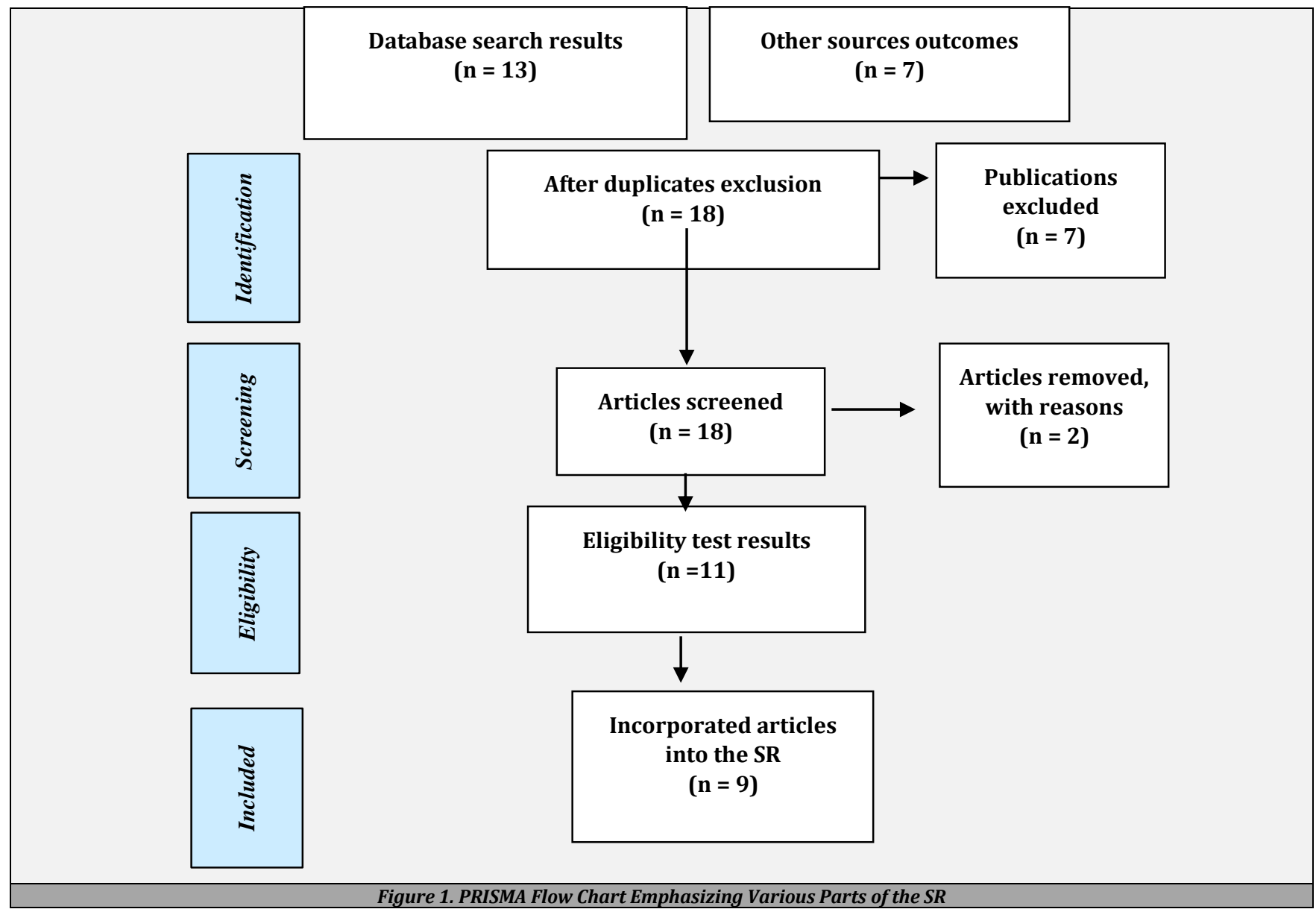

\begin{tabular}{|c|c|c|c|}
\hline Author (s) & Year & Study Design & Outcomes \\
\hline Hamdy A. & 2015 & In-vitro Study & $\begin{array}{l}\text { Endocrowns have the highest fracture } \\
\text { resistance, meaning they have a high } \\
\text { success rate. }\end{array}$ \\
\hline $\begin{array}{l}\text { Otto and } \\
\text { Mörmann }{ }^{15}\end{array}$ & 2015 & Clinical & $\begin{array}{l}\text { Survival of shoulder crowns was } \\
\text { better than endocrowns at the end of } \\
12 \text { years }\end{array}$ \\
\hline $\begin{array}{l}\text { Schmidlin et } \\
\mathrm{al}^{16}\end{array}$ & 2015 & In-vitro & $\begin{array}{l}\text { Lower resistance to fracture was } \\
\text { reported for the endocrowns. }\end{array}$ \\
\hline $\begin{array}{l}\text { Borgia B et } \\
\mathrm{al}^{17}\end{array}$ & 2016 & $\begin{array}{c}\text { A Retrospective } \\
\text { Patient Series Study }\end{array}$ & $\begin{array}{l}\text { Endocrowns are aesthetic and } \\
\text { conservative technique sensitive } \\
\text { processes utilized to restore posterior } \\
\text { ETT, and they possess desirable } \\
\text { features like functional and } \\
\text { biomechanical performance. }\end{array}$ \\
\hline $\begin{array}{l}\text { Belleflamme } \\
\quad \text { et al }{ }^{18}\end{array}$ & 2017 & Clinical & $\begin{array}{l}\text { Survival rate of endocrowns was } \\
\text { reported to be } 99 \% \text { at at } 44.7 \\
\text { months. }\end{array}$ \\
\hline Atash et a ${ }^{19}$ & 2017 & In-vitro & $\begin{array}{l}\text { Greater resistance to fracture was } \\
\text { reported for the endocrowns. }\end{array}$ \\
\hline Fages et $\mathrm{al}^{20}$ & 2017 & Clinical & $\begin{array}{l}\text { Much more favourable survival rate } \\
\text { for endocrowns on molars. }\end{array}$ \\
\hline Altier $\mathrm{M}$ et $\mathrm{al}^{21}$ & 2018 & In-vitro & $\begin{array}{c}\text { The lithium disilicate ceramic } \\
\text { endocrowns have a higher resistance } \\
\text { to fracture than composite groups, } \\
\text { which means they have a high success } \\
\text { rate. }\end{array}$ \\
\hline Einhorn et al 22 & 2019 & In-vitro & $\begin{array}{l}\text { Standard endocrowns exhibit } \\
\text { resistance to failure than ferrule- } \\
\text { containing endocrown preparations. }\end{array}$ \\
\hline
\end{tabular}

Altier et al. ${ }^{21}$ explain that a specific type of endocrown referred to as the lithium disilicate ceramic endocrowns have a higher resistance to fracture when compared to another composite group of endocrowns. This finding means that the lithium disilicate ceramic endocrowns have a high success rate. In another study, the success rate of standard and ferrule containing endocrown preparations was compared and it was found that standard endocrowns exhibit resistance to failure than ferrule containing endocrown preparations. ${ }^{22}$ Lastly, Borgia et al $^{17}$ claim that endocrowns are aesthetic and conservative technique sensitive processes utilized to restore posterior ETT, and they possess desirable features like functional and biomechanical performance. These findings suggest that endocrowns have a high success rate in restorative dentistry. Therefore, they should be used more often. The success and long life of endocrowns are accounted by four main factors: accurate tooth preparation, choosing exact restorative and bonding materials, and vigilant selection of cases including type of tooth, margin locations and residual sound tissue. ${ }^{23}$

\section{CONCLUSIONS}

This systematic literature review has provided a step-wise process that can be used by other scholars and researchers who would like to investigate the indications and success rate of endocrowns in restorative dentistry. The protocol, if adhered to, can lead to the same results highlighted above. The 
SR has found that endocrowns possess specific qualities and characteristics that make it useful and efficient in restorative dentistry. Most importantly, those features make endocrowns display high success rates when used in restorative dentistry. Some of those characteristics include resistance to fracture and high functional and biomechanical performance. Even though all the articles included in this SR agree that endocrowns are a desirable restorative tool in dentistry, more investigations should be done to ascertain that fact. For instance, further research should be conducted to assess their utilization in treating different types of dental conditions. Similarly, other systematic reviews and meta-analyses with a significant number of included publications and studies should be conducted to expand the generalizability potential of such results. Regardless, at the moment, it can be concluded that endocrowns are suitable tools that should be utilized frequently in restorative dentistry for ETT with extensive coronal tissue loss as a substitute to fixed partial dentures and conventional post-core. They offer better aesthetics and mechanical performance, low cost, and short clinical time, as compared to traditional techniques.

Financial or other competing interests: None.

Disclosure forms provided by the authors are available with the full text of this article at jemds.com.

\section{REFERENCES}

[1] Sevimli G, Cengiz S, Oruc MS. Endocrowns: review. J Istanb Univ Fac Dent 2015;49(2):57-63.

[2] de Carvalho MA, Lazari PC, Gresnigt M, et al. Current options concerning the endodontically-treated teeth restoration with the adhesive approach. Braz Oral Res 2018;32(Suppl 1):e74.

[3] Ma OS, Nicholls JI, Junge T, et al. Load fatigue of teeth with different ferrule lengths, restored with fiber posts, composite resin cores, and allceramic crowns. J Prosthet Dent 2009;102(4):229-34.

[4] Zarow M, Devoto W, Saracinelli M. Reconstruction of endodontically treated posterior teeth-with or without post? Guidelines for the dental practitioner. Eur J Esthet Dent 2009;4(4):312- 27.

[5] Sorensen JA, Engelman MJ. Effect of post adaptation on fracture resistance of endodontically treated teeth. J Prosthet Dent 1990;64(4):419-24.

[6] Dogui H, Abdelmalek F, Amor A, et al. Endocrown: an alternative approach for restoring endodontically treated molars with large coronal destruction. Case Rep Dent 2018;2018:1581952.

[7] Greenhalgh T, Thorne S, Malterud K. Time to challenge the spurious hierarchy of systematic over narrative reviews? Eur J Clin Invest 2018;48(6):e12931.

[8] O’Donohoe TJ, Dhillon R, Bridson TL, et al. Reporting quality of systematic review abstracts published in leading neurosurgical journals: a research on research study. Neurosurgery 2019;85(1):1 - 10.
[9] Page MJ, Shamseer L, Tricco, AC. Registration of systematic reviews in PROSPERO: 30,000 records and counting. Systematic Reviews 2018;7(1):32.

[10] Yang H, Lee HJ. Research trend visualization by MeSH terms from PubMed. Int J Environ Res Public Health 2018;15(6):1113.

[11] Leydesdorff L, Comins JA, Sorensen AA, et al. Cited references and Medical Subject Headings (MeSH) as two different knowledge representations: clustering and mappings at the paper level. Scientometrics 2016;109(3):2077 - 91.

[12] Rocca GT, Saratti CM, Poncet A, et al. The influence of FRCs reinforcement on marginal adaptation of CAD/CAM composite resin endocrowns after simulated fatigue loading. Odontology 2016;104(2):220 - 32.

[13] Helal MA, Wang Z. Biomechanical assessment of restored mandibular molar by endocrown in comparison to a glass fiber post - retained conventional crown: 3D finite element analysis. J Prosthodont 2019;28(9):988 - 96.

[14] Hamdy A. Effect of full coverage, endocrowns, onlays, inlays restorations on fracture resistance of endodontically treated molars. Journal of Dental and Oral Health 2015;1(5):1 -5.

[15] Otto T, Mörmann WH. Clinical performance of chairside CAD/CAM feldspathic ceramic posterior shoulder crowns and endocrowns up to 12 years. Int J Comput Dent 2015;18(2):147-61.

[16] Schmidlin PR, Stawarczyk B, DeAbreu D, et al. Fracture resistance of endodontically treated teeth without ferrule using a novel H-shaped short post. Quintessence Int 2015;46(2):97 - 108.

[17] Borgia BE, Barón R, Borgia JL, et al. Endocrowns: a retrospective patient series study, in an 8-to-19-year period. Odontoestomatología 2016;18(28):45 - 56.

[18] Belleflamme MM, Geerts SO, Louwette MM, et al. No post - no core approach to restore severely damaged posterior teeth: an up to 10-year retrospective study of documented endocrown cases. J Dent 2017;63:1 - 7.

[19] Atash R, Arab M, Duterme H, et al. Comparison of resistance to fracture between three types of permanent restorations subjected to shear force: an in vitro study. J Indian Prosthodont Soc 2017;17(3):239 - 49.

[20] Fages M, Raynal J, Tramini P, et al. Chairside computeraided design/computer-aided manufacture all- ceramic crown and endocrown restorations: a 7-year survival rate study. Int J Prosthodont 2017;30(6):556-60.

[21] Altier M, Erol F, Yildirim G, et al. Fracture resistance and failure modes of lithium disilicate or composite endocrowns. Niger J Clin Pract 2018;21(7):821- 6.

[22] Einhorn M, DuVall N, Wajdowicz M, et al. Preparation ferrule design effect on endocrown failure resistance. J Prosthodont 2019;28(1):e237 - 42.

[23] Tzimas K, Tsiafitsa M, Gerasimou P, et al. Endocrown restorations for extensively damaged posterior teeth: clinical performance of three cases. Restor Dent Endod 2018;43(4):e38. 